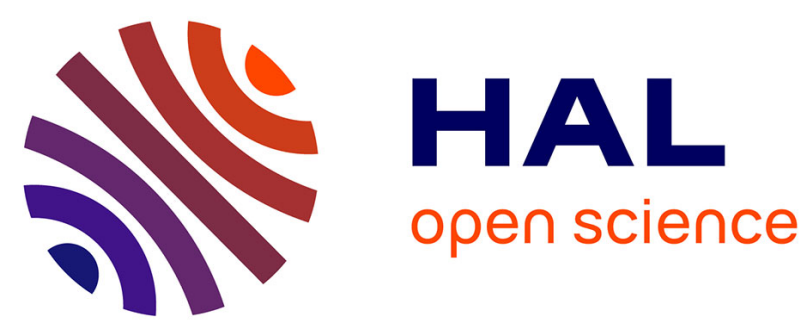

\title{
Les endocannabinoïdes stimulent la synthèse protéique dans un modèle de myotubes en culture
}

\author{
Olivier Le Bacquer, Kristell Combe, Yves Boirie, Stephane Walrand
}

\section{To cite this version:}

Olivier Le Bacquer, Kristell Combe, Yves Boirie, Stephane Walrand. Les endocannabinoïdes stimulent la synthèse protéique dans un modèle de myotubes en culture. JFN 2017, Journées Francophones de Nutrition, Dec 2017, Nantes, France. 2017. hal-02734569

\section{HAL Id: hal-02734569 \\ https://hal.inrae.fr/hal-02734569}

Submitted on 2 Jun 2020

HAL is a multi-disciplinary open access archive for the deposit and dissemination of scientific research documents, whether they are published or not. The documents may come from teaching and research institutions in France or abroad, or from public or private research centers.
L'archive ouverte pluridisciplinaire HAL, est destinée au dépôt et à la diffusion de documents scientifiques de niveau recherche, publiés ou non, émanant des établissements d'enseignement et de recherche français ou étrangers, des laboratoires publics ou privés.

\section{(ㅇ)(1) $\$$}

Distributed under a Creative Commons Attribution - NonCommercial - NoDerivatives 44.0 
Les endocannabinoïdes stimulent la synthèse protéique dans un modèle de myotubes en culture.

Olivier Le Bacquer ${ }^{1,2}$, Kristell Combe ${ }^{1,2}$, Yves Boirie ${ }^{1,2,3}$, Stéphane Walrand ${ }^{1,2}$

${ }^{1}$ UMR 1019, Unité de Nutrition Humaine, INRA/Université d'Auvergne, Clermont-Ferrand

${ }^{2}$ Clermont Université, Université d'Auvergne, Unité de Nutrition Humaine, Clermont-Ferrand, France

${ }^{3} \mathrm{CHU}$ Clermont-Ferrand, Service de Nutrition Clinique, Clermont-Ferrand, France

Introduction: Le système endocannabinoïde est impliqué dans le contrôle de la prise alimentaire, du métabolisme énergétique, et participe au développement de l'obésité et du diabète de type 2 . Ce système, présent dans la plupart des tissus, comprend des ligands endogènes spécifiques, appelés endocannabinoïdes (EC) tels que l'anandamide (AEA) et le 2-arachidonoyl glycerol (2AG), leur système enzymatique de synthèse et de dégradation et au moins deux récepteurs $C B 1$ et $C B 2$. Au niveau musculaire, quelques études ont montré le contrôle de la signalisation de l'insuline et de la captation du glucose par les EC. II a également été montré que le système endocannabinoïde régule la différenciation musculaire et est capable de moduler les capacités oxydatives du muscle, probablement via la biogenèse mitochondriale, comme précédemment observé dans les cellules neuronales. L'objectif de cette étude était de déterminer l'impact d'un traitement court aux endocannabinoïdes sur la synthèse protéique musculaire.

Matériels et méthodes: Après différenciation, des cellules $\mathrm{C} 2 \mathrm{C} 12$ (modèle de myotubes en culture) ont été incubées en présence de doses croissantes (100nM-25 $\mu \mathrm{M})$ d'agonistes (AEA, ACEA, et 2-AG) ou d'agoniste inverse (rimonabant) au récepteur CB1. La synthèse protéique a été mesurée par Western Blot en utilisant la technique SUnSET (incorporation de puromycine dans les protéines naissantes). L'activation des voies Akt, mTOR et ERK a été quantifiée par Western Blot. Les résultats ont été analysés par ANOVA à une voie et exprimés en moyenne \pm sem.

Résultats : L'incubation en présence de $2 A G$ ou d'ACEA ne modifie pas la synthèse protéique de cellules C2C12 différenciées. Après $6 \mathrm{~h}$ d'incubation, la synthèse protéique musculaire est accrue de $80 \%$ en présence de $10 \mu \mathrm{M} d^{\prime} A E A(p<0.01)$ et de $150 \%$ en présence de $10 \mu \mathrm{M}$ de rimonabant $(p<0.01)$. Cet effet de l'AEA et du rimonabant est dose- et temps-dépendant avec un effet maximal pour une dose de $10 \mu \mathrm{M}$ et une durée d'incubation de $6 \mathrm{~h}(\mathrm{p}<0.01)$. Les états de phosphorylation d'Akt, de la S6K et de ERK1/2 ne sont pas modifiés par ces traitements. La stimulation de la synthèse protéique induite par le rimonabant est diminuée en présence d'AEA $(p<0.05)$, ce qui suggère une compétition entre l'AEA et le rimonabant.

Conclusion: Dans des cellules $\mathrm{C} 2 \mathrm{C} 12$, une incubation courte (1-6h) en présence d'AEA ou de rimonabant induit une stimulation de la synthèse protéique. Cet effet ne semble pas faire intervenir les voies Akt, mTOR ou ERK1/2. 